\title{
LA COLMENA Y EL HORMIGUERO: UNA LECTURA ECO-CRÍTICA DE CIEN AÑOS DE SOLEDAD
}

\author{
Beehive and anthill: An eco-critical reading about \\ Cien años de soledad
}

Josefa Lago Graña*

\begin{abstract}
RESUMEN
Este ensayo se ocupa de estudiar la presencia de las hormigas y las abejas en la novela Cien años de soledad, y de establecer conexiones entre las estructuras sociales en que viven ambas especies y la sociedad de Macondo, señalando elementos asociados con lo masculino en el hormiguero, y con lo femenino en el caso de la colmena. La teoría crítica del eco-feminismo nos ayudará a entender el efecto que el desarrollo tecnológico y social de la sociedad industrial de occidente tiene en el equilibrio natural, y en las causas del declive físico y social de Macondo. Para ello se analiza la escena de la ascensión de Remedios, la única en que se menciona a la abeja reina en toda la novela, junto a las múltiples apariciones de las hormigas coloradas en los últimos capítulos, para ofrecer una interpretación de la casa de los Buendía como una colmena, dominada por las mujeres, pero amenazada por las fuerzas destructoras masculinas, representadas por las hormigas, que ponen en peligro la estabilidad social. Según esta lectura, la aniquilación final del pueblo ocurre al no poder mantener el equilibrio entre el orden natural y el social.
\end{abstract}

Palabras clave: Eco-feminismo, hormiguero, colmena, Macondo, naturaleza, sociedad.

\begin{abstract}
This article studies the presence of ants and bees in the novel One Hundred Years of Solitude, and the connections established between the social structures those species live in and the town of Macondo, pointing out those elements that connect masculine traits with anthills, and feminine ones with beehives. Ecofeminist critical theory will help explain the effects of technical and social development in the natural world, as in the social and physical decline of Macondo. To that end the scene of Remedies assumption will be analyzed, this being the only point in the novel the queen bee is mentioned. We will also look at the many appearances of the red ants at the end of the novel, to offer a reading of the Buendía house as a beehive ruled by women, but threatened by the red ants that work as male destructive forces, endangering social stability. This reading posits that Macondo's demise is due to the broken balance between the natural and the social orders.
\end{abstract}

Key Words: Ecofeminism, anthill, beehive, Macondo, nature, society.

Profesora Distinguida en el Programa de Estudios Hispánicos en la Universidad de Puget Sound en Tacoma, Washington. Estados Unidos.

Correo electrónico: jlago@pugetsound.edu

Recepción: 04/03/2014. Aceptación: 30/06/2014. 
La estructura familiar y social de los seres humanos ha sido, desde sus primeras manifestaciones, altamente compleja y organizada con frecuencia de forma claramente jerárquica. Pero las estructuras sociales organizadas en grupos familiares no son exclusivas de las sociedades humanas, ya que numerosas comunidades animales presentan una organización social tan compleja y jerárquica como la humana, y con frecuencia más eficiente en su funcionamiento: tal es el caso de manadas de lobos, familias de leones, bandadas de pájaros, o colmenas de abejas. La novela de García Márquez Cien años de soledad nos permite conocer a las personas que habitan el pueblo de Macondo, una comunidad que en sus inicios presenta una estructura social que se acerca a la utopía socialista arcádica pero se convierte en un lugar gobernado por una rígida organización militar jerárquica, para terminar en un estado de caos, abandono y olvido, del que nunca se recupera y en el que desaparece. Cada una de estas fases por las que pasa Macondo se conecta directamente con un personaje masculino de los que allí habitan: el fundador José Arcadio Buendía representa la fase inicial, su hijo el coronel Aureliano Buendía la segunda, y el tataranieto Aureliano Babilonia la última.

Por otra parte, muchos de los personajes en la novela aparecen con frecuencia conectados a animales, sea por similitud física, actitud, características, o asociación: la cola de cerdo con todos los hombres Buendía, los gallos de pelea con el patriarca José Arcadio, imágenes de gata y comadreja con Amaranta Úrsula, de salamandra con Amaranta, de rana con Úrsula, de tortuga con Aureliano Segundo, y una fuerte relación de Petra Cotes con vacas, conejos y mulas. Además de estas conexiones hay numerosos ejemplos por toda la novela de presencia animal en grupos y sociedades organizadas, con múltiples referencias a insectos como mariposas, termitas, y hormigas, referencias que incrementan en intensidad y asiduidad a medida que la novela -y el destino de Macondo, toca a su fin. En el caso de Macondo y su microcosmo la casa de los Buendía, la conexión más clara entre la estructura familiar y una sociedad animal se encuentra con el hormiguero, y de forma más sutil pero igual de sólida, con la colmena.

La imagen del hormiguero es clara y hay numerosos ejemplos en los últimos capítulos de la novela del papel destructor de las hormigas coloradas, que se van apoderando palmo a palmo del territorio de los Buendía hasta que destruyen la casa desde la periferia hasta su mismo centro, literalmente comiéndose al último vástago de la familia, el bebé con la cola de cerdo. La figura de la colmena, otro ejemplo de sociedad animal altamente desarrollada, aparece de forma menos extendida, pero hay una escena importante en el centro del texto que no debe ser ignorada. Ocurre en el capítulo 12, cuando se describe la ascensión (o asunción, para subrayar las connotaciones religiosas) de Remedios, la bella, quien, en medio del quehacer de tender la ropa lavada a secar, inicia una levitación que la lleva, junto con las valiosas sábanas de bramante de Fernanda del Carpio, a subir a los cielos. Con este acto, Remedios cumple por fin, según el narrador, "su irrevocable destino de abeja reina" (García Márquez 1984: 350). La conexión de Remedios con la abeja reina resulta hermética cuando examinamos este personaje con respecto al papel de la abeja reina en el contexto social de la colmena y con respecto al valor semántico social conectado al "síndrome de abeja reina ${ }^{1}$," poniendo de relevancia el significado e implicaciones de la referencia en el contexto de la novela, y el papel de una abeja reina en la estructura natural de la colmena, así como de las mujeres consideradas "abejas reina" en la sociedad industrial occidental contemporánea.

Este ensayo se ocupa de estudiar la presencia y función en la novela Cien años de soledad de las hormigas coloradas por una parte, y de las abejas reina por otra, y de establecer conexiones entre las estructuras sociales en que viven ambas especies y la sociedad establecida en Macondo (en particular el grupo familiar residente en la casa de los Buendía), señalando algunos elementos asociados con lo masculino que se aprecian en ecosistema del hormiguero, y con lo femenino en el caso de la sociedad apícola de la colmena. La teoría crítica del ecofeminismo nos ayudará a entender el efecto 
que el desarrollo tecnológico y social de la sociedad industrial de occidente tiene en el equilibrio natural, y en las causas del declive físico y social de Macondo. Para ello se analiza la escena de la ascensión de Remedios, la única en que se menciona a la abeja reina en toda la novela, junto a las múltiples apariciones de las hormigas coloradas en los últimos capítulos, para ofrecer una interpretación de la casa de los Buendía, y por extensión Macondo, como una colmena poblada por una serie de abejas-reina que dominan la dinámica doméstica una a la vez (Úrsula, Fernanda, y Amaranta Úrsula), rodeadas de abejas-obrera (Pilar, Visitación, Santa Sofía, Petra, Nigromanta) y zánganos (todos los hombres Buendía, y alguna mujer, como Amaranta), amenazada por las fuerzas destructoras masculinas que amenazan la estabilidad de la sociedad matriarcal. Según esta lectura, la aniquilación final del pueblo ocurre porque la sociedad macondina no es capaz de mantener el equilibrio entre el orden natural y el social. La última abeja reina (Amaranta Úrsula) muere sin dejar descendencia (ya que el bebé es devorado por las hormigas) y la colmena no puede existir solo con la presencia del zángano (Aureliano). Sin la abeja reina, la colmena es abandonada, provocando esto el apocalipsis final del universo de la novela.

Como marco teórico, este estudio sigue los planteamientos de la crítica eco-feminista, que señala la larga asociación establecida entre la mujer y el mundo natural, y analiza la construcción cultural del mundo natural, a través del análisis del lenguaje, el deseo, el conocimiento, y el poder (Legler 1997: 227), anotando además que la tradición intelectual occidental ha devaluado todo lo asociado con lo femenino, lo emocional, lo animal, lo natural, y lo corporal, mientras que ha elevado lo asociado con lo masculino, lo racional, lo espiritual, y lo humano (Gaard 1993: 5). Para Gaard, la premisa básica del eco-feminismo es que las ideologías que consienten la opresión por razones de raza, clase, género, orientación sexual, o aptitud física, son las mismas ideologías que toleran la opresión de la naturaleza (1993: 1). Legler añade que la identificación de la naturaleza como ente femenino perpetúa estructuras jerárquicas impuestas por la cultura patriarcal que devalúan tanto lo natural como lo femenino: "Constructions of nature as female (as mother/ virgin) are essential to the maintenance of hierarchical ways of thinking that justify the oppression of various 'others' in patriarchal culture by ranking them 'closer' to nature or by declaring their practices 'natural' or 'unnatural"' (1997: 228). Charlene Spretnak asevera que hay una estrecha correlación en las culturas eurocéntricas en la forma de percibir tanto a la mujer como las fuerzas de la naturaleza, que es con temor, resentimiento, y desprecio. Es por esto que según ella, las tradiciones espirituales occidentales buscan llegar a lo inmaterial y lo trascendental alejándose de los elementos corporales, en particular los que están conectados al cuerpo femenino y sus procesos naturales (1993: 261).

A partir de los planteamientos de los primeros grupos feministas formados en los años sesenta y setenta, cuyo objetivo fundamental era la lucha por la igualdad de género eliminando leyes discriminatorias vigentes en los terrenos legal, educativo, y económico (Tong 2009: 48), el feminismo radical asevera que las diferencias de género (lo masculino y lo femenino) son constructos sociales no necesariamente conectados con las diferencias de sexo (hombre y mujer), e insisten que la sociedad patriarcal ha impuesto una serie de características de lo femenino que tienen como objeto mantener a las mujeres en un papel pasivo y a los hombres en uno activo (Tong 2009: 51). Kate Millett afirmó que las relaciones entre mujeres y hombres se basan en un sistema de poder y, para eliminar el poder masculino sobre la mujer, hay que desterrar primero el concepto de género construido por el sistema patriarcal, ya que este sistema exagera las diferencias entre hombres y mujeres, asegurándose de que los hombres ocupan la parte dominante, o masculina, y las mujeres la subordinada, o femenina (1970: 13).

Mientras que Millett y otras feministas radicales adjudicaban las diferencias entre hombres y mujeres a factores sociales, Marilyn French avanzó las teorías feministas al relacionar 
esas diferencias a cuestiones biológicas. French examina el origen de la sociedad patriarcal y especula que las primeras sociedades humanas eran probablemente matriarcales, en las que todos los individuos del clan veían a la mujer como el fundamento de la supervivencia del grupo como tal, y a la naturaleza que los rodeaba y de la que dependían, como amiga y apoyo a la estabilidad social. A medida que las sociedades evolucionaron y los grupos sociales crecieron en número y en tamaño, la comida se hizo escasa y fue necesario tomar control de los recursos naturales y dominar a la naturaleza para extraer de ella lo necesario para la supervivencia del grupo. Este proceso produjo la alienación de los humanos con respecto al mundo natural, y resultó en una relación hostil y de enemistad entre hombre y naturaleza. Según French, no es sorprendente que estos sentimientos negativos aumentaran el deseo del hombre de controlar no solo la naturaleza sino también a las mujeres, dada la estrecha conexión entre ambas, sobre todo por el aspecto reproductivo conectado con la mujer (1985: 67).

Las tendencias feministas más recientes han empezado a recuperar la asociación de la mujer con el mundo natural, y a redefinirla en términos positivos. Linda Vance explica que "[s]ome cultural feminists have chosen to reclaim the long association of woman with earth, with nature, with the intuitive and spiritual, and to redefine that association as vital to sanity and survival, celebrating it through ritual and action" (1993: 125). Las transformaciones experimentadas por las teorías feministas occidentales que han devenido de esta nueva forma de percibir la conexión de la mujer con la naturaleza, y los esfuerzos de las mujeres por salvar la Tierra son los elementos que, según Irene Diamond y Gloria Feman Orenstein, definen el eco-feminismo (1990: ix). Las activistas, teóricas y artistas feministas redefinieron esta conexión por medio de textos escritos, antiguos rituales reinventados, y un activismo social que conectaba la devastación del planeta con la explotación de la mujer. Después de problematizar dualidades generalmente aceptadas, como cultura/naturaleza, razón/ emoción, o humano/animal, el objetivo del ecofeminismo, sostienen Diamond y Orenstein, es tejer nuevas historias que reconozcan y valoren la diversidad biológica y cultural que mantiene a todos los seres vivos (1990: xi). Raymond Williams mantiene que García Márquez presenta una relación ambigua entre el mundo humano y el no-humano, sin favorecer a uno sobre el otro. El autor implícito, según Williams, se siente atraído a la vez por la oralidad y por la escritura, por la tecnología y por la naturaleza, por la modernidad y por la tradición, pero también es muy crítico de esos conceptos (2010: 75). En su lectura eco-crítica de la novela, la presencia y gradual pérdida de la cultura oral, conectada con Úrsula, paralela la presencia y la pérdida gradual de la naturaleza, dada la conexión entre cultura oral y el mundo natural (2010: 74).

La dicotomía entre naturaleza y tecnología, tradición y modernidad, o civilización y barbarie que se observa en Cien años de soledad aparece ampliamente prefigurada en numerosos textos de la tradición literaria hispánica, como Williams anota al mencionar la influencia de textos como María de Jorge Isaacs, La vorágine de José Eustasio Rivera, y Doña Bárbara de Rómulo Gallegos (2010: 67-9). Asimismo, tanto la colmena como el hormiguero aparecen en la literatura con interpretaciones simbólicas. El famoso cuento de Horacio Quiroga "La miel silvestre" combina ambas estructuras sociales animales. En ese cuento, abejas y hormigas colaboran para restaurar el orden natural, el equilibrio perturbado por la llegada a la selva de Gabriel Benincasa, el "muchacho pacífico, gordinflón y de cara rosada" (1967: 125) que representa la civilización y la falta de respeto por el poder y el orden de la naturaleza. La miel envenenada y las hormigas carnívoras llamadas la "corrección" restauran el orden natural de la selva cuando eliminan la amenaza que Benincasa representa, primero paralizándolo con la miel, después comiéndoselo hasta que solo queda de él el fusil "winchester" con el que quería defenderse de las "fieras" y las botas "stromboots" con las que había protegido su cuerpo y pisado el "monte crepuscular y silencioso" (1967: 127). Ambos objetos resultan 
inútiles para luchar contra el enemigo real (las abejas y las hormigas), y son los únicos restos que quedan para probarlos inútiles contra las fuerzas de la naturaleza.

La estructura social de una colmena y un hormiguero presenta un gran número de paralelos: en los dos grupos existen tres categorías principales: reina, machos (llamados “zánganos" en el caso de las abejas), y obreras ${ }^{2}$. En ambas especies el bien común está por encima del interés individual; en las dos existe una jerarquía clara, con todos los miembros del grupo cumpliendo un papel predeterminado y claramente delineado, que llevan a cabo sin excepción; sus “casas" se adaptan perfectamente a las necesidades del grupo y son ejemplos magníficos de arquitectura e ingeniería natural ${ }^{3}$. Sin embargo, las asociaciones que generalmente formamos los humanos con respecto a estas dos especies se diferencian claramente en varios puntos: mientras que el hormiguero es imagen de destrucción (con túneles excavados en la tierra), la colmena representa construcción (ya que las abejas construyen un espacio material, discreto, y arquitectónicamente diferenciado de su entorno). Los hormigueros son vistos como una peste o una invasión, son una presencia no bienvenida, mientras que las colmenas se ven con aprecio, por la presencia de la sabrosa miel y la útil cera ${ }^{4}$. Incluso hay una ciencia, la apicultura, que busca formar y cuidar colmenas por su beneficio a los humanos, mientras que a las hormigas se busca destruirlas y alejarlas de las habitaciones humanas. Por otra parte, a las hormigas se las admira por su laboriosidad y su compromiso a la comunidad, pero se las desprecia por su falta de individualismo. Por su parte, las abejas también son laboriosas, pero los zánganos son el prototipo de pereza y abandono.

Estas asociaciones llevan a conectar la colmena con algunos de los personajes femeninos de la novela, por el carácter industrioso y trabajador de personajes como Úrsula, Santa Sofía y Amaranta Úrsula, mientras que el hormiguero se vincula más con los masculinos, por el elemento de caos y destrucción asociado con la mayoría de los hombres Buendía, en especial el coronel Aureliano, pero también el patriarca José Arcadio, su hijo y el hijo de este, Arcadio, y los gemelos José Arcadio Segundo y Aureliano Segundo. Por otra parte, con frecuencia se han estudiado los personajes femeninos de Cien años de soledad desde una perspectiva arquetípica, dividiéndolos entre mujeres malas (Pilar, Rebeca, Petra, Meme, y Amaranta Úrsula) y buenas (Úrsula, Amaranta y Fernanda 5 ), o asignándoles papeles representativos de las clasificaciones arquetípicas, como por ejemplo hacen Deveny y Marcos al dividir los personajes según encajen en el modelo patriarcal (Úrsula, Pilar, Rebeca, Amaranta y Fernanda), modelo servil (Visitación, Santa Sofía, Argénida, y Remedios Moscote) y modelo rebelde (Meme y Amaranta Úrsula ${ }^{6}$ ). Raymond Williams, a su vez, conecta a los personajes masculinos con el mundo de la escritura, y a los femeninos con la cultura oral. Explica que en Macondo, como en la mayoría de las sociedades tradicionales, los hombres (Melquíades y José Arcadio especialmente) son instruidos y educados en las letras, mientras que las mujeres (Úrsula en particular) piensa y se expresa de forma consistente como una persona que pertenece a la cultura oral (2010: 74). Muchos otros críticos coinciden en señalar diferencias fundamentales entre la mayoría de los personajes masculinos y la mayoría de los personajes femeninos. Mario Vargas Llosa es probablemente el primero en realizar un estudio exhaustivo de la novela en su libro de 1971 García Márquez: Historia de un deicidio, en el que presenta al hombre Buendía como "amo y señor del mundo" (1971: 504) mientras que las mujeres están sometidas al marido o al padre, pero tienen control del recinto privado del hogar, y ejercen "una autoridad ilimitada sobre los hijos” (1971: 505). Explica en detalle que:

\footnotetext{
El rasgo familiar dominante es la inferioridad de la mujer, la división estricta de funciones que perdura los cien años de la estirpe: los varones son los miembros activos y productores, los que trabajan, se enriquecen, guerrean, y se lanzan en aventuras descabelladas, en tanto que la función de las mujeres es permanecer en el hogar y ocuparse de las tareas domésticas, como barrer, cocinar, fregar, bordar; en tiempos difíciles, pueden improvisar
} 
algún negocio casero, como los animalitos de caramelo que vende Úrsula (1971: 504).

En El olor de la guayaba cuando Plinio Apuleyo comenta: "En CAS las mujeres ponen el orden allí donde los hombres introducen el caos. ¿Es tu visión del papel histórico de los dos sexos?" (1993: 137), el mismo García Márquez responde que "[e]sto me ha hecho pensar que las mujeres carecen de sentido histórico: en efecto, de no ser así, no podrían cumplir su función primordial de las mujeres es perpetuar la especie" (1993: 137). Muchos años más tarde, la opinión de los críticos, sobre todo hombres, continúa en la misma vena. Irvine Winsboro señala que:

The Buendía men are brooding, introverted, licentious, and impulsive, frequently too impulsive for the women of the family. For their part, the Buendía women are continually concerned with keeping the family together in a dynastic sense. They are stern, naive, and sometimes sexually wanton, but generally they are the mothers and custodians of the Buendía male line. (1993: 154)

Una lectura eco-crítica de la novela, sin embargo, nos ofrece una visión un tanto diferente de los personajes masculinos y femeninos. Estudiar la relación entre Macondo y su entorno natural, desde su génesis hasta su apocalipsis, revela la evolución de una estructura social utópica local a un caos distópico global. En sus inicios, después de su fundación, Macondo es un pueblo arcádico donde "[e]l mundo era tan reciente, que muchas cosas carecían de nombre, y para mencionarlas había que señalarlas con el dedo" (1984: 83). El pequeño pueblo de 300 habitantes es feliz en tanto que todos están en armonía con la naturaleza. La visión armónica aparece particularmente simbolizada en la casa de los Buendía, con "una salita amplia y bien iluminada, un comedor en forma de terraza con flores de colores alegres, dos dormitorios, un patio con un castaño gigantesco, un huerto bien plantado, y un corral donde vivían en comunidad pacífica los chivos, los cerdos y las gallinas" (1984: 92-3). Sin embargo, pronto la llegada de la tecnología traída por los gitanos (magistralmente ejemplificada en el bloque de hielo de la primera escena de la novela) altera la paz y el orden natural, llevando al patriarca José Arcadio Buendía a la demencia. Nuevas oleadas de gitanos con otras novedades provocan la huida del primogénito de la familia, causando a su vez la salida de Úrsula en su busca. La desaparición de Úrsula del ámbito doméstico trae un cambio drástico en la estructura familiar de los Buendía. Efectivamente, el patriarca se ve obligado a cuidar a la recién nacida Amaranta y hacerse cargo de la casa, invirtiendo así la jerarquía social tradicional que asigna roles específicos a mujeres (la casa y otros espacios interiores y privados) y a hombres (la calle y otros espacios abiertos y públicos). Úrsula ocupa, durante su viaje al exterior de Macondo, el papel asignado al hombre, explorando la selva y conociendo a gente nueva, mientras que su marido ocupa la esfera doméstica, un universo limitado y cerrado.

Cada nuevo grupo que llega a Macondo introduce en el pueblo un avance científico, tecnológico o social que altera y distorsiona el ritmo del pueblo y de la familia, y aleja a Macondo progresivamente del contacto con el mundo natural: podemos pensar por ejemplo en la manera en que José Arcadio sustituye los pájaros que dan la hora con sus trinos con relojes musicales (traídos por los primeros árabes que llegan al pueblo) sincronizados para dar la hora a ritmo de vals, de forma mecánica e independientemente del horario solar (1984: 130). O la forma en que José Arcadio Segundo se dedica a "la descomunal empresa de romper piedras, excavar canales, despejar escollos y hasta emparejar cataratas" (1984: 303) hasta alterar el curso del río para poder traer el barco de vapor hasta Macondo. El capítulo $12^{7}$ abre con la llegada de la modernidad, tomando por sorpresa a los macondinos, que tratan en vano de aceptar y absorber las novedades tecnológicas de principios del siglo XX:

Deslumbrada por tantas y tan maravillosas invenciones, la gente de Macondo no sabía por dónde empezar a asombrarse, Se trasnochaban contemplando las pálidas bombillas eléctricas alimentadas por la planta que llevó Aureliano Triste en el segundo viaje del tren, y a cuyo obsesionante 


\begin{abstract}
tumtum costó tiempo y trabajo acostumbrarse. Se indignaron con las imágenes vivas que el próspero comerciante don Bruno Crespi proyectaba en el teatro con taquillas de bocas de león, porque un personaje muerto y sepultado en una película, y por cuya desgracia se derramaron lágrimas de aflicción, reapareció vivo y convertido en árabe en la película siguiente (1984: 335).
\end{abstract}

Mientras los habitantes de Macondo van del deslumbramiento a la sorpresa y del desconcierto a la desilusión entre los muchos aparatos, invenciones y artilugios que llegan en el tren, se produce la llegada de "el rechoncho y sonriente míster Herbert" (1984: 337) quien, después de probar los bananos locales, cambiará para siempre la historia de Macondo, que al poco tiempo de la llegada de Jack Brown, se transforma "en un campamento de casas de madera con techos de cinc, poblado por forasteros que llegaban de medio mundo en el tren, no sólo en los asientos y plataformas, sino hasta en el techo de los vagones" (1984: 339). De todos los cambios que afectan el desarrollo del pueblo, el caso más radical, que significa el principio del fin para Macondo, es la llegada de la compañía bananera, que causa un cambio fundamental en el paisaje natural de la región, cuando zonas enteras de selva son taladas para dar paso a plantaciones de banano y la antigua región encantada, "el paraíso de humedad y silencio, anterior al pecado original, donde las botas se hundían en pozos de aceites humeantes y los machetes destrozaban lirios sangrientos y salamandras doradas" (1984: 96) son ahora "umbrosas e interminables plantaciones de banano" (1984: 409). El intento de dominación total de la naturaleza por parte de la compañía bananera (recordemos que la compañía intenta controlar la lluvia) produce el diluvio que dura casi cinco años, al final del cual la compañía gringa ha desaparecido y Macondo está en ruinas, pero más cerca ahora de sus orígenes como pueblo conectado a sus raíces naturales en la región.

Es en este tumultuoso ambiente que Remedios, la bella, llega a la adolescencia. Sin embargo, muy pronto resulta claro que Remedios no es como el resto de las mujeres Buendía o como ninguna otra persona: "Remedios, la bella, fue la única que permaneció inmune a la peste del banano. Se estancó en una adolescencia magnífica, cada vez más impermeable a los formalismos, más indiferente a la malicia y la suspicacia, feliz en un mundo propio de realidades simples" (1984: 342-3). De raparse el pelo, a vestirse solamente con un simple camisón de tela de saco, a llevar un horario indiferente al reloj, a pasarse horas en la bañera, Remedios ignora las convenciones sociales, no por afán de rebeldía, sino porque no tienen ningún sentido para ella. Su inconformismo social la lleva a ser tachada de boba por algunos (como su tía-abuela Amaranta), y de lúcida por otros (como el coronel Aureliano Buendía). Pero para todos queda claro que Remedios no encaja ni en la familia Buendía, ni en el pueblo Macondo, ni en ningún otro lugar terrestre. Por eso, cuando ocurre la escena de la ascensión, nadie reacciona con sorpresa, como si el acto fuera algo esperado:

Amaranta sintió un temblor misterioso en los
encajes de sus pollerinas y trató de agarrarse
de la sábana para no caer, en el instante en que
Remedios, la bella, empezaba a elevarse. Úrsula,
ya casi ciega, fue la única que tuvo serenidad para
identificar la naturaleza de aquel viento irreparable,
y dejó las sábanas a merced de la luz, viendo a
Remedios, la bella, que le decía adiós con la mano,
entre el deslumbrante aleteo de las sábanas que
subían con ella, que abandonaban con ella el aire
de los escarabajos y las dalias, y pasaban con ella
a través del aire donde terminaban las cuatro de la
tarde, y se perdieron con ella para siempre en los
altos aires donde no podían alcanzarla ni los más
altos pájaros de la memoria (1984: 355 ).

La reacción al suceso es variada: mientras que la mayoría del pueblo lo interpreta como un milagro y "se encendieron velas y se rezaron novenarios" (1984: 355) en clásica tradición católica, otros lo interpretan como una mentira inventada por la familia para "salvar la honra" (1984: 355) de Remedios. Es en este contexto que el narrador nos informa que "[1] os forasteros, por supuesto, pensaron que Remedios, la bella, había sucumbido por fin a su irrevocable destino de abeja reina" (1984: 350) creando la implicación de que Remedios se había fugado con algún 
hombre y la familia quería ocultar el pecado probando en cambio la santidad de la joven. La lectura que propone este ensayo equipara a las mujeres Buendía con abejas que habitan la colmena que es la casa de los Buendía. En el momento de la ascensión de Remedios, Fernanda es la abeja reina, habiendo dado tres hijos a su esposo Aureliano Segundo y dominando de forma rotunda la dinámica familiar ${ }^{8}$. En la colmena solamente puede existir una abeja reina a la vez, de manera que no hay espacio en ella para Remedios. La hermosa joven abandona la colmena en el momento en que la compañía bananera impacta el progreso de Macondo de tal manera que el precario equilibrio mantenido hasta entonces entre el mundo natural y la sociedad humana se rompe de forma irreparable.

La lluvia que asola Macondo durante casi cinco años y que expulsa a la compañía bananera de la región también funciona como instrumento equilibrador de situaciones en que la naturaleza ha perdido territorio frente a la civilización. Al final de la lluvia, el mundo natural redobla sus ataques contra los instrumentos de civilización y envía sus soldados, las cucarachas, las termitas, el comején, y sobre todo, las hormigas coloradas, para socavar (literalmente) los cimientos sobre los que se asienta Macondo y su símbolo principal, la casa blanca de los Buendía. Cuando el diluvio por fin termina y los macondinos salen del periodo de hibernación forzada en sus casas, "Macondo estaba en ruinas" (1984: 449). Úrsula, ciega y centenaria, se dispone a reconstruir y restaurar la casa por tercera vez. En esta ocasión, sin embargo, su edad y sus fuerzas no son suficientes para luchar contra las plagas que asolan la casa:

Moviéndose a tientas por los dormitorios vacíos percibía el trueno continuo del comején taladrando las maderas, y el tijereteo de la polilla en los roperos, y el estrépito devastador de las enormes hormigas coloradas que habían prosperado en el diluvio y estaban socavando los cimientos de la casa. Un día abrió el baúl de los santos, y tuvo que pedir auxilio a Santa Sofía de la Piedad para quitarse de encima las cucarachas que saltaron del interior, y que ya habían pulverizado la ropa (455).
A pesar del tamaño y la voracidad de los insectos, Úrsula persevera en su misión de contener las fuerzas naturales en su intento de recuperar para sí el espacio robado por los humanos. Por el momento, parece que Úrsula va a tener éxito, y que la casa va a volver a su estado antediluviano: "Puso al sol las escasas ropas que todavía estaban en condiciones de ser usadas, ahuyentó las cucarachas con sorpresivos asaltos de insecticida, raspó las venas del comején en puertas y ventanas y asfixió con cal viva a las hormigas en sus madrigueras" (1984: 455).

Las primeras menciones de "las enormes hormigas coloradas" (1984: 455) ocurren en el capítulo 17, después del fin de la lluvia y como parte de una nueva plaga que amenaza la casa de los Buendía y que Úrsula se dispone a eliminar con sus últimas fuerzas 9 . A partir de ese momento, todos los capítulos restantes tienen múltiples menciones del progreso inexorable de los insectos en su invasión progresiva de la casa, así como los esfuerzos de Úrsula, Santa Sofía y por último Amaranta Úrsula por, no ya eliminarlas, pero al menos mantenerlas a raya a base de cal. Sin embargo, a la muerte de Úrsula, está claro que la naturaleza está ganando la partida y es inexorable en su ataque, a la vez que presenta a los insectos como una fuerza intencionalmente invasiva, con la misión clara de invadir, dominar, y quedarse:

Sin tiempo ni recursos para impedir los desafueros
de la naturaleza, Santa Sofía de la Piedad se pasaba
el día en los dormitorios, espantando los lagartos
que volverían a meterse por la noche. Una mañana
vio que las hormigas coloradas abandonaron
los cimientos socavados, atravesaron el jardín,
subieron por los pasamanos donde las begonias
habían adquirido un color de tierra, y entraron hasta
el fondo de la casa. Trató primero de matarlas con
una escoba, luego con insecticida y por último con
cal, pero al otro día estaban otra vez en el mismo
lugar, pasando siempre, tenaces e invencibles
$\left(1984: 483^{10}\right)$.

La llegada de Amaranta Úrsula en el capítulo 19 se augura como la oportunidad de reiniciar la historia familiar empezando con la restauración de la casa a su antiguo esplendor, y recuperar a su vez la conexión armónica con 
el mundo natural. Durante un momento parece que Úrsula ha vuelto a la casa y que una vuelta a la edad de oro aún es posible cuando Amaranta Úrsula "[d]esbandó las hormigas coloradas que ya se habían apoderado del corredor, resucitó los rosales, arrancó la maleza de raíz, y volvió a sembrar helechos, oréganos y begonias en los tiestos del pasamanos" (1984: 503). Poco después se prefigura ya el fin, la victoria de las hormigas en dominar la casa, incluso el último reducto hasta ahora a salvo, el dormitorio, y la muerte del recién nacido devorado por las hormigas: "Una noche se embadurnaron de pies a cabeza con melocotones en almíbar, se lamieron como perros y se amaron como locos en el piso del corredor, y fueron despertados por un torrente de hormigas carniceras que se disponían a devorarlos vivos" (1984: 536 $6^{11}$ ).

Según la afirmación del propio García Márquez en El olor de la guayaba de que "la función primordial de las mujeres es perpetuar la especie" (1993: 137), Amaranta Úrsula, al final de la novela, falla en esta "función primordial" al no poder mantener vivo a su hijo. Cuando muere en el parto, y deja a Aureliano como único responsable del bebé, es inevitable que este muera, ya que Aureliano, como zángano, no está capacitado para otra función más que aparearse con la reina para asegurar que esta perpetúe la especie. Al morir la reina, la colmena se dispersa. En este caso, además, falta el tercer elemento de la estructura social, la abeja obrera que cuide y alimente a la siguiente generación, como lo hicieron Úrsula, Visitación y Santa Sofía en el pasado. De hecho, el bebé con cola de cerdo es el primer y único Buendía que nace después de la muerte de Úrsula, en el único momento en que la casa-colmena está solamente ocupada por la reina y el zángano.

Durante el embarazo de Amaranta Úrsula en el último capítulo, la convivencia desigual y forzada de abejas y hormigas en la casa blanca tiene los días contados: la colmena ve reducido su territorio día a día: "Cercados por la voracidad de la naturaleza, Aureliano y Amaranta Úrsula seguían cultivando el orégano y las begonias y defendían su mundo con demarcaciones de cal, construyendo las últimas trincheras de la guerra inmemorial entre el hombre y las hormigas" (1984: 541). Pronto este mundo se reduce al espacio del dormitorio, la cámara real donde reside la abeja reina y donde se aparea con el zángano. La colmena ha sido invadida y solo queda por proteger de la invasión esta cámara donde se lleva a cabo la ceremonia de apareamiento que tiene como misión la perpetuación de la especie: "En el aturdimiento de la pasión, vio las hormigas devastando el jardín, saciando su hambre prehistórica en las maderas de la casa, y vio el torrente de lava viva apoderándose otra vez del corredor, pero solamente se preocupó de combatirlo cuando lo encontró en su dormitorio" (1984: 535)

Aureliano por fin lee su presente y su pasado en la profecía contenida en los manuscritos de Melquíades que en ese momento cumplen 100 años y pueden por fin ser leídos. La profecía describe el fracaso de los Buendía de conservar el equilibrio con el entorno natural, representado tanto por la flora como por la fauna, y como consecuencia "el primero de la estirpe está amarrado en un árbol, y al último se lo están comiendo las hormigas" (1984: 547). La destrucción del universo textual de Macondo nos enseña que de nosotros depende la salvación de nuestro medio ambiente terrestre. La pérdida de contacto con la naturaleza y el desequilibrio entre el mundo natural y la ultramecanización de la sociedad llamada "desarrollada" va a tener nefastas consecuencias. La crítica eco-feminista muestra que la mujer tiene una conexión más estrecha que el hombre con el mundo natural y esa es una conexión que debe ser imitada a escala social, en vez de ser devaluada y reprimida como lo ha sido durante siglos. Solo así podremos evitar la desgracia que se avecina y que García Márquez predijo, no solo en su más famosa novela, sino en un pequeño artículo de opinión que ofreció como respuesta a la pregunta propuesta por la revista Time en 1992 "¿Cuáles son las prioridades de la humanidad para las próximas décadas?”:

La humanidad está condenada a desaparecer en el siglo XXI por la degradación del medio ambiente. El poder masculino ha demostrado que no podrá impedirlo, por su 
incapacidad de sobreponerse a sus intereses. Para la mujer, en cambio, la preservación del medio ambiente es una vocación genética. Es apenas un ejemplo. Pero, aunque solo fuera por eso, la inversión de poderes es de vida o muerte (1992: np).

\section{Notas}

1. La expresión "síndrome de abeja reina" fue acuñado en los años 70, después de un estudio comandado por investigadores de la Universidad de Michigan, que examinaron las tasas de ascenso y el impacto del movimiento feminista en el campo laboral. En un artículo publicado en 1974 en la revista Psychology Today, los investigadores presentaron sus hallazgos, basados en más de 20.000 respuestas a su encuesta. Encontraron que las mujeres que alcanzan el éxito en entornos dominados por hombres eran a veces propensas a frenar el ascenso de otras mujeres. Esto ocurría, según sus argumentos, en gran parte porque la cultura patriarcal del trabajo motivaba a las pocas mujeres que llegaban a la cima a obsesionarse con mantener su autoridad.

2. Los machos provienen de huevos no fecundados y las obreras de huevos fecundados. Algunas obreras también pueden poner huevos en casos de ausencia de la reina, aunque estos siempre dan como resultado machos, ya que son huevos sin fertilizar.

3. El libro de Juan Antonio Ramírez La metáfora de la colmena. De Gaudi a Le Corbusier se ocupa de identificar elementos arquitectónicos centrales a la sociedad occidental moderna que toman como modelo e inspiración la estructura de la colmena.

4. Es interesante que las abejas se afanan para producir algo que no necesitan, que para ellas es un deshecho (la miel y la cera), aunque muy apreciado para el consumo humano.

5. Para una explicación detallada de esta lectura, véanse los trabajos de Vargas Llosa Historia de un deicidio (1971), Margaret Sayens Peden "Las buenas y las malas mujeres de Macondo" (1976) y Ernesto Volkening "Gabriel García Márquez, o el tropic desembrujado" (1969), entre otros.

6. El libro de Seymour Menton Historia verdadera del realismo mágico (1998) y el artículo de Laura Verónica Rodríguez Imbriaco "Una lectura arquetípica de los personajes femeninos de Cien años de soledad" (2008) entre otros también contienen un análisis junguiano que organiza a las mujeres en arquetipos fijos.

7. La novela no tiene capítulos numerados pero consta de 20 secciones claramente diferenciadas, cada una de unas 20 páginas. Por motivos prácticos usamos el término capítulo para referirnos a las partes o secciones.

8. En la casa de los Buendía hay pocas abejas reinas -pero en su mayoría los vástagos no nacen de abejas reinas sino de obreras, siendo los casos más claros Pilar y Santa Sofía, quienes producen zánganos (Arcadio y Aureliano José; y Remedios, Aureliano Segundo y José Arcadio Segundo).

9. En el capítulo 13 hay dos menciones de las hormigas voladoras que prefiguran la muerte inminente del coronel Aureliano Buendía. Estos insectos son biológica y simbólicamente diferentes de la especie que aparece más tarde.

10. La alusión a la vuelta inexorable de las hormigas y su reaparición en la casa a pesar de los intentos de aniquilación de Santa Sofía sugieren una interpretación simbólica de la presencia de estos insectos. La conexión entre las hormigas y la atemporalidad o lo eterno es familiar en las artes plásticas. La pintura "La persistencia de la memoria" de Salvador Dalí presenta un grupo de hormigas sobre la tapa de un reloj de bolsillo, mientras que los grabados del artista holandés M.C. Escher representan bandas de Moebius sobre las que caminan hormigas. Agradezco al doctor Jorge Chen esta valiosa observación, compartida en conversaciones durante el congreso Cuatro Esquinas que se celebró en Colorado en 2013.

11. Al contrario de lo que ocurre en la novela, el incesto es una tendencia natural y una práctica común en muchas especies animales que viven en sociedades cerradas y dependen de la endogamia para asegurar la pervivencia de la comunidad. En la colmena, la reina se aparea con sus "hermanos" o "tíos", ya que todos nacen de la reina o de alguna obrera hermana de la reina.

\section{Referencias}

Deveny, John., Marcos Juan Manuel. 1988. Women and Society in One Hundred 
Years of Solitude." Journal of Popular Culture 22(1): 83-90.

Diamond, Irene., Gloria Feman Oreinstein. 1990. (eds.) Reweaving the World. The Emergence of Ecofeminism. San Francisco: Sierra Club Books, 1990. Print

French, Marilyn. 1985. Beyond Power: On Women, Men, and Morals. New York: Summit Books.

Gaard, Greta. 1993. Living Interconnections with Animals and Nature. Ecofeminism: Women, Animals, Nature. Ed. Greta Gaard. Philadelphia: Temple UP.

García Márquez, Gabriel. 1984. Cien años de soledad. Ed. Jacques Joset. Madrid: Cátedra, (c 1967).

1993. El olor de la guayaba. Conversaciones con Plinio Apuleyo Mendoza. México: Diana, (c 1982).

- ¿Cuáles son las prioridades de la humanidad para las próximas décadas? Time Magazine Octubre, 15, 1992: 74-77.

Legler, Gretchen. 1997. Ecofeminist Literary Criticism. Ecofeminism: Women, Culture, Nature. Ed. Karen J. Warren. Bloomington: Indiana UP.
Millett, Kate. 1970. Sexual Politics. Garden City, N.Y.: Doubleday.

Quiroga, Horacio. 1967. La miel silvestre. Cuentos de amor, de locura y de muerte. Buenos Aires: Losada.

Spretnak, Charlene. 1993. Earthbody and Personal Body as Sacred. Ecofeminism and the Sacred. Ed. Carol J. Adams. New York: Continuum.

Tong, Rosemarie. 2009. Feminist Thought. A More Comprehensive Introduction. Boulder: Westview Press.

Vance, Linda. 1993. Ecofeminism and the politics of reality. Ecofeminism: Women, Animals, Nature. Ed. Greta Gaard. Philadelphia: Temple UP.

Vargas Llosa, Mario. 1971. García Márquez: Historia de un deicidio. Barcelona: Seix Barral.

Williams, Raymond. 2010. An eco-critical Reading of One Hundred Years of Solitude. The Cambridge Companion to Gabriel Garcia Marquez. Ed. Philip Swanson. Cambridge: Cambridg UP.

Winsboro, Irvin. 1993. Latin American Women in Literature and Reality: García Márquez's One Hundred Years of Solitude. Midwest Quarterly, 34(2): 151-160. 
